\title{
História da Educação e História da Filosofia: culturas cruzadas a partir das concepções de história e de escrita da história em Hegel
}

\author{
Carlos Eduardo Vieira *
}

\begin{abstract}
Resumo: Neste artigo visamos discutir possíveis impactos da escrita da História da Filosofia sobre a escrita da História da Educação, a partir da análise das concepções de história e de escrita da história presentes na obra de Georg Wilhelm Friedrich Hegel. Neste estudo Hegelé concebido como um autor que sintetizou e disseminou uma visão da história presente de forma dispersa e fragmentada na cultura historiográfica do século XIX. Ele reafirmou conceitualmente e metodologicamente as imemoriais crenças na virtuosidade e no papel edificante das idéias (Espírito), bem como produziu uma interpretação do passado, capaz de apaziguar o sentimento de dilaceramento da cultura, ao conciliar história, ontologia e lógica. Nos limites deste trabalho exploramos o potencial heurístico da tópica hegeliana, sem, contudo, pretendermos analisar empiricamente os seus efeitos na historiografia da educação brasileira.
\end{abstract}

Palavras-chave: História da Educação; História da Filosofia; Hegel; historiografia.

\section{History of educational and history of philosophy: cultures put together from Hegel's conceptions of history and history writing}

Abstract: This article is aimed at arguing about possible impacts of writings on the History of Philosophy on writing on the History of Education, from the analysis of Georg Wilhelm Friedrich Hegel's conceptions of history and its writing. In this study Hegel is conceived as an author who synthesized and spread a conception of history that can be seen as dispersed and fragmented in the historiographical culture of the nineteenth century. In a conceptual and methodological way, he reaffirmed the immemorial beliefs in virtuosity and the enlightening role of ideas (Spirit). He also produced an interpretation of the past which colud reduce the feeling of cultural laceration by conciliating history, ontology and logic. This paper explores the heuristic potential of the Hegelian view, though without empirically analyzing its effects on the Brazilian education historiography.

Key words: History of Education; History of Philosophy; Hegel; historiography.

* Professor do Programa de Pós-Graduação em Educação, Linha de Pesquisa História e Historiografia da Educação, da Universidade Federal do Paraná, Brasil. Pesquisador do Conselho Nacional de Desenvolvimento Científico e Tecnológico - CNPq. Professor visitante na University of Cambridge, UK. cevieira9@gmail.com 
É corrente nas análises sobre a historiografia da educação a constatação da expressiva presença no campo, em períodos que variam, nas diferentes tradiçôes nacionais, do gênero História das Idéias Pedagógicas ${ }^{1}$. Essas narrativas mostram-se intimamente associadas ao modelo da História da Filosofia e da sua variante História das Idéias $^{2}$. A ênfase sobre o significado das idéias e das correntes de pensamento; a organização cronológica dos capítulos; a estruturação de um cânone de obras e de autores consagrados; a relação indireta com as fontes; e, sobretudo, a análise das idéias a partir de um método internalista são características gerais que aproximam as escritas da História das Idéias Pedagógicas e da História da Filosofia ${ }^{3}$. São inúmeros os exemplos de obras de História da Educação, produzidas nas Américas ou na Europa, que abordaram historicamente o fenômeno educativo nos marcos desse modelo de escrita. É possível afirmar que esse tipo de História da Educação pode ser representado, também, como uma especialidade da História da Filosofia que se ocupa especificamente de questôes formativas presentes nos textos filosóficos consagrados. Dessa maneira, as teorias de Platão, Rousseau, Kant, Locke, Dewey, entre outros tão

I. A publicação, em 2006, do livro Pesquisa em História da Educação no Brasil, organizado por José Gondra, confirma, a partir de estudos realizados em todas as regiões brasileiras, a presença regular e significativa do gênero História das Idéias Pedagógicas na produção do campo da História da Educação no Brasil. Deste livro, gostaríamos de destacar o capítulo intitulado "História da Educação no Estado de São Paulo: a configuração do campo e a produção atual ( 1943-2003)", no qual Diana Vidal, Paula Perin Vicentini e outros mostram como a História das Idéias Pedagógicas foi o gênero predominante nas teses e dissertações das principais universidades do Estado de São Paulo, de 1943 a 2003. Desse ponto em diante, usaremos a denominação História das Idéias Pedagógicas para nos referirmos ao gênero de escrita da História da Educação que tem sido denominado de diferentes maneiras; entre as variantes mais comuns estão História da Pedagogia, História do Pensamento Educacional ou História da Pedagogia.

2. Sobre a história da História da Filosofia e a História das Idéias, ver, entre outros, Alasdair Mac Intyre, La relación de la filosofia con su passado; Bruce Kubrick, Siete pensadores y como crecieron: Descartes, Espinoza, Leibniz; Locke, Berkeley, Hume e Kant; Donald R. Kelley, The descent of ideas: the history of intellectual history; Lorenz Kruger, Por qué estudiamos la historia de la filosofia?; Quentin Skinner, La filosofia en la historia: ensayos de historiografia de la filosofia. Todas as obras citadas nas notas de rodapé têm sua referência completa nas referências bibliográficas deste estudo.

3. O método internalista supõe, em síntese, a investigação das idéias, sem considerar seus contextos de produção, de maneira a privilegiar o movimento lógico do pensamento presente nos textos canônicos das diferentes áreas. Nessa perspectiva, o processo de produção das idéias não sofre espécie alguma de constrangimento ou de determinação oriundos de outros contextos, sejam eles econômicos, políticos ou sociais. Pelo contrário, quando as relações entre idéias e outros contextos sociais mais amplos são tratadas, elas aparecem em um sentido unívoco de determinação do plano espiritual sobre o plano das práticas sociais.

Pro-Posiçōes, Campinas, v. 20, n. 1 (58), p. 189-205, jan./abr. 2009 
célebres, compõem o cânone de filosofias e de personagens presentes nesses textos. No caso do Brasil, a título de exemplo entre os manuais didáticos, poderíamos destacar o livro Noções de História da Educação, de Afrânio Peixoto, de 1933. Nas Noções, a história da educação foi tratada como evolução das idéias pedagógicas, revelando uma concepção da escrita apoiada sobre as crenças na onipotência e na onipresença das idéias na estruturação dos processos formativos da antiguidade ao mundo contemporâneo. A obra de Peixoto é um bom exemplo da força desse modelo, pois, apesar de sua formação como médico e cientista natural, ele adotou o modo filosófico de estruturação da História da Educação, enfatizando o poder e a centralidade das idéias pedagógicas. Para além de Peixoto, constatamos um conjunto significativo de textos vinculados ao gênero História das Idéias Pedagógicas que tem mantido, no caso brasileiro, freqüência significativa e regular no campo, ao longo dos últimos setenta anos ${ }^{4}$. Essa forma de escrita produzida na interseção entre a História da Filosofia e a História da Educação tem sido criticada; contudo, não recebeu um tratamento específico na perspectiva de problematizar as implicações dessa relação 5 .

Nesse sentido, visamos neste artigo analisar a concepção de história e de escrita da História da Filosofia, em particular as idéias sobre esses temas sustentadas pela obra de Georg Wilhelm Friedrich Hegel (1770-1831). Realizaremos primeiramente uma exposição sintética da concepção de história presente na obra de Hegel, pois acreditamos que a compreensão da arquitetura lógica dessa escrita permite a elaboração de uma crítica de parte significativa de textos associados ao campo da História da Educação. Logo, reiteramos, não

4. Entre as obras que servem de suporte empírico para esta pesquisa e que relevam — com maior ou menor intensidade, direta ou indiretamente - a interseção entre as escritas da História da Filosofia e a História da Educação, destacamos as seguintes: GILES, T. R. História da Educação. São Paulo: EPU, 1987; MARROU, H. História da Educação na antiguidade. 4. ed. São Paulo: EPU, 1975; FIGUEIREDO, J. C. Fundamentos históricos e filosóficos da educação. 2. ed. Belo Horizonte: Júpiter, [197-]; COSTA, C. et al. Grandes educadores. Rio de Janeiro Globo: 1949; AGAZZI, A. Historia de la filosofia y de la pedagogia. 2. ed. Marfil, 197I 3 v; MORENO, J. M. Historia de la Educacion. 2. ed. Madrid: Paranifo, 1974; LUZURIAGA, L. História da Educação e da Pedagogía. 2. ed. São Paulo: Companhia Editora Nacional, 1963; LEIF, J; RUSTIN, G. Pedagogia Geral: pelo estudo das doutrinas pedagógicas. São Paulo: Companhia Editora Nacional, 1960; ZULUAGA, I. G. Historia de la Educacion. 3. ed. Madrid: ITER, I970; NUNES, Ruy A. da C. N. História da Educação na Antiguidade Cristã. São Paulo: EPU, 1978; NUNES, R. A. da C. N. História da Educação no século XVII. São Paulo: EPU, 198I; SANTOS, T. M. Noções de História da Educação. 3. ed. São Paulo: Companhia Editora Nacional, 195I; PEIXOTO, A. Noções de História da Educação. 3. ed. São Paulo: Companhia Editora Nacional, 1942.

5. Sobre esta crítica, ver, entre outros, A História da Educação no Brasil, de Marta Carvalho; Questões teóricas e de método: a História da Educação nos marcos de uma disciplina, Mirian Warde; Ensino e historiografia da educação: problematização de uma hipótese, de Clarice Nunes; História e historiografia: as escritas recentes da história da educação brasileira (197|- 1988), de Luis Carlos Barreira. 
faremos neste espaço uma análise particularizada de obras de História da Educação, mas sim buscaremos estruturar uma hipótese analítica capaz de problematizar a espécie de História da Educação que se apoiou, como revelam os estudos da área, no modelo de escrita da História da Filosofia. Sendo assim, nos limites deste trabalho, exploramos o potencial heurístico da tópica hegeliana, sem, contudo, pretender analisar exaustivamente os seus impactos na historiografia da educação brasileira.

Em síntese, as pretensões deste artigo são, tão-somente, expor de forma sintética a concepção hegeliana da história e, a partir desta representação da história, postular elementos para uma crítica da escrita da História da Educação que poderá ser útil para analisar as narrativas histórico-educacionais que visam interpretar a história intelectual do campo, bem como a presença de idéias e de teorias pedagógicas em diferentes contextos espaciais e temporais.

\section{Hegel: a História da Filosofia é a Filosofia}

A História da Filosofia constituiu-se em disciplina tradicional na formação dos filósofos, tendo como principais funções: problematizar a filosofia, à medida que confronta os resultados obtidos pela tradição; afirmar a identidade do campo, de maneira a delimitar o cânone de autores, obras e filosofias, bem como circunscrever o léxico filosófico; e, por fim, formar as novas gerações que, antes de produzir saber reconhecido e legitimado na área, necessitam conhecer e reconhecer-se entre as escolas, as tradições, os modos de escrever e de conceitualizar a filosofia ${ }^{6}$. É possível afirmarmos, apesar dos riscos das generalizações, que as histórias especiais, tais como a História da Arte e da Educação, assumiram, guardadas as suas especificidades, funções similares à História da Filosofia na definição e na delimitação dos seus respectivos campos. Narrativas elaboradas a partir de razões próprias dos campos disciplinares, os quais, geralmente, não mantêm relações diretas e regulares com as pesquisas produzidas no campo da história ${ }^{7}$ e aos quais elas estão vinculadas.

A História da Filosofia conta, se comparada com outras histórias especializadas, com uma extensa tradição. Poderíamos lembrar Theophrastus

6. Não é incomum — considerando, por exemplo, o tempo histórico e as tradições nacionais percebermos variações no cânone filosófico. Sobre este tema ver, entre outros, Bruce Kubrick, Siete pensadores y como crecieron: Descartes, Espinoza, Leibniz; Locke, Berkeley, Hume; Kant.

7. $\bigcirc$ conceito de campo de Pierre Bourdieu não se constitui em um aparato heurístico central neste texto; contudo, quando utilizamos a expressão, estamos apoiados na idéia bourdiana que define o campo como espaço social de relações onde são estabelecidos/impostos os critérios de nomeação, de classificação e de distinção social. Bourdieu ressalta a relação entre os campos, mas sustenta, também, a autonomia relativa desses espaços. 
(372-287 a.C.) e o seu texto Physikón Doxai como um indício remoto desse esforço de sistematizar e de criticar o conhecimento produzido no passado no âmbito da filosofia da escola peripatética. Não obstante, cremos que este exemplo esteja no limite do anacronismo, pois, nesse contexto, o próprio significado de filosofia não corresponde ao sentido conferido pelo século XVIII, quando percebemos o vicejar do gênero História da Filosofia na cultura filosófica. As obras monumentais da tradição alemã representadas por Johann Brucker (Historia Critica Philosophiae, 1742-44, 6 v.), Johann Buhle (Lehrbuch der Geschichte der Philosophie, 1796-1804, 8 v.), Dietrich Tiedemann (Geist der spekulativen Philosophie von Thales bis Berkeley, 1791-97, 6 v.) e Gottlieb Tennemann (Geschichte der Philosophie, 1789-1819, 11 v.) expressam este movimento em relação à história. Nos séculos XIX e XX, transcendendo as fronteiras germânicas, esse processo intensificou-se e, assim, conhecemos inúmeros filósofos historiadores, tais como Victor Cousin (1792-1867) na França, Wilhelm Dilthey (1833-1911) e Ernest Cassirer (1874-1945) na Alemanha, Benedetto Croce (1866-1952) na Itália e Arthur Lovejoy (1873-1962) nos Estados Unidos da América.

Para além do significado pontual desses pensadores, no passado ou no presente, gostaríamos de destacar, no século XIX, o pensamento de Hegel, pois acreditamos que ele se tenha tornado uma matriz paradigmática de escrita da História da Filosofia, que reverberou de forma intensa na História das Idéias e nas histórias de campos particulares que assumiram as idéias, sejam elas científicas, religiosas, estéticas ou educativas, como objetos privilegiados de análise dos processos culturais ${ }^{8}$. Hegel assumiu essa condição de modelo de escrita da História da Filosofia na medida em que ele defendeu a identidade entre a filosofia e a sua história. O estudo histórico da filosofia encontrou em Hegel razões filosóficas, ou melhor, constituiu-se no modo, por excelência, de produzir a filosofia. Esta concepção, exposta por Hegel em textos particularmente voltados para esse fim, colocou a história no centro do debate filosófico, na medida em que esta opção não significou o abandono do caráter edificante da filosofia. Em termos propriamente hegelianos, o conhecimento histórico da filosofia propicia pensar a evolução e o desenvolvimento do espírito no tempo e, sobretudo, operar a síntese racional que articula os resultados atingidos pela objetivação da razão na história. O olhar para o passado não significa distanci-

8. A presença de Hegel na cultura historiográfica dos séculos $X I X$ e $X X$ representou um fenômeno de grande proporção. Parte significativa do chamado historicismo alemão (Historismus) que, em certa medida, está na base da inserção da História no rol das disciplinas acadêmicas e científicas de prestígio nas universidades européias, produziu-se em diálogo com as idéias hegelianas, seja buscando demonstrar através da pesquisa histórica teses caras à filosofia da história hegeliana ou, em sentido oposto, buscando negá-las. Sobre este tema, ver The German Conception of History: The national tradition of historical thought from Herder to the present, escrito por George G. Iggers. 
ar-se dos projetos filosóficos em disputa no presente, pois a história do pensamento anuncia o percurso lógico da filosofia contemporânea; entendida, nessa perspectiva, como síntese integradora da saga do espírito do mundo. A exposição desse movimento dialético imanente ao processo de afirmação da razão na história (objetivação, negação e síntese) demanda a elaboração de uma forma particular de escrita que, segundo Hegel, diferencia-se radicalmente da tradicional forma de pensar e de escrever a história por parte dos historiadores.

\section{História da Filosofia: a identidade entre as histórias da razão e da cultura}

Hegel afirmava que, em uma época na qual prevalece o historicismo, perdese a capacidade de pensar o espírito em construção. Uma época que trata "tudo historicamente, então se ocupa somente de um mundo que já não existe e divaga pelas casas dos defuntos, porque o espírito renuncia a sua própria vida que consiste em pensar-se a si mesmo" (Hegel, 1986, p.56). O pensamento, produtor de todas as realidades, não tem "nenhum interesse no que é morto, no que é passado. Isto só tem interesse para a erudição, para a vaidade" (Hegel, 1986, p.56).

À primeira vista essas palavras soam como avessas à história como campo de pesquisa e como modo de reflexão privilegiado da filosofia; contudo, foram proferidas pelo filósofo, que incluiu de maneira particular a história na elaboração do seu pensamento. A história, para Hegel, não é uma questão no interior do seu sistema, mas sim um dos seus fundamentos. Logo, se não era a história o problema, a questão incidia sobre as concepçôes de história e de escrita da história presentes no contexto intelectual hegeliano. No centro de um debate disciplinar marcado — na própria expressão de Hegel, pelos limites estabelecidos por Kant à filosofia e pelo crescimento da respeitabilidade da História no plano acadêmico —-, ele realizou um projeto teórico de grande fôlego: retomar a iniciativa teórica em campos abandonados pela filosofia da reflexão, ao mesmo tempo que postulava um entendimento racionalista e realista da história, que confrontava o empirismo e a erudição dos historiadores românticos.

Para Hegel, existem três modos de narrar a história. A história original que, fundada por Heródoto e Tucídides, procede à descrição dos acontecimentos presentes, sem transcendê-los. A história reflexiva, que se divide em quatro possibilidades: história universal, gênero em que o historiador transcende o seu tempo e mesmo as possibilidades do material empírico através de sínteses ordenadoras do processo histórico; história pragmática, que procura fazer uma análise causal da história, identificando causa e efeito no processo histórico; história crítica, gênero amplamente disseminado na Alemanha, que é a história 
da história ou a historiografia; e a última variação da história reflexiva é a que se apresenta como história fragmentada, isto é, história da arte, da literatura, da lei e da religião. O terceiro modo de escrever a história é o filosófico (Hegel, 1990, p.45-52).

Nas duas primeiras formas de escrita, a história original e a história reflexiva, o pensamento está subordinado aos acontecimentos; no modo filosófico ocorre o contrário. $\mathrm{O}$ papel do historiador reflexivo é reconstituir os acontecimentos na forma de representações que ordenem os dados empíricos. O modo filosófico de narrar o passado traz para a História, segundo Hegel, o conceito de razão. A história do mundo deve ser descrita à luz da idéia racional, dos juízos que permitem as conexões necessárias entre a razão que governa o mundo e o seu processo histórico de exteriorização na cultura.

A História da Filosofia, para Hegel, não é a descrição da multiplicidade de filosofias, pois esse procedimento revela a inutilidade da própria filosofia. A filosofia dos filósofos particulares, narrada sem uma preocupação de sistematizar o movimento evolutivo do espírito, aparece como uma sucessão de opiniões dispostas no tempo. É preciso sempre lembrar que, para Hegel, o espírito valese de filósofos particulares para objetivar-se, mas transcende-os no tempo. Para narrar a História da Filosofia, a partir do entendimento da filosofia como evolução necessária da idéia no tempo, necessita-se de uma filosofia, isto é, de um sistema de pensamento que apreenda a evolução da idéia no seu processo de objetivação na mundanidade. A história particular dos indivíduos — nas suas trajetórias de paixão, fortuna e virtude - é objeto do historiador, enquanto ao filósofo cabe a história dos universais, do concreto, do movimento da racionalidade na história.

A presença da razão na história não está associada à supremacia da virtude (arete) dos indivíduos, das culturas e/ou do Estado considerados isoladamente, pois muitas atrocidades são necessárias para o desenvolvimento do espírito no tempo. Na expressão de Hegel, muita flor inocente será esmagada no turbilhão histórico da realização do projeto racional. A ação de César, ao restringir a democracia em Roma e reinstituir a autocracia, justifica-se, aos olhos de Hegel, como a realização do destino racional da sua época. Os heróis, os homens de negócio do espírito do mundo, têm a fonte de suas açôes no "espírito interior, ainda oculto por baixo da superfície, mas já batendo contra o mundo exterior como em uma casca para, afinal, irromper, deixando-a em pedaços" (Hegel, 1990, p.79) ${ }^{9}$. Hegel descreve, na expressão de Hyppolite, a trajetória pancrática

9. A esse respeito, é importante levar em conta a posição hegeliana sobre o indivíduo na história, particularmente a passagem da Razão na História (p.67-87), em que Hegel trata dos quatro tipos de homens do ponto de vista histórico: o cidadão, o indivíduo, o herói e a vítima. 
da história em termos panlógicos, isto é, a lógica na história manifesta-se sempre como tragédia, como morte, como dor e decadência, dado que na história do mundo o Absoluto se manifesta somente parcialmente em cada cultura. As civilizações exprimem e não exprimem o Absoluto, logo morrem e se transformam. Na gênese histórica da filosofia está a civilização grega, e o surgimento desse tipo de manifestação cultural marca o prenúncio da decadência dessa cultura. A decadência da cidade-Estado proporcionou a filosofia grega, assim como a queda da República romana e a ascensão dos demagogos propiciaram a filosofia neoplatônica. Essa é a conexão necessária da filosofia com as outras formas de manifestação do espírito de uma época (zeitgeist).

A filosofia só nasce quando o espírito já demonstra um grau de desenvolvimento no âmbito político, artístico e religioso. Para que

um povo filosofe, convém que já tenha alcançado um certo grau de cultura intelectual. Tem que ter havido preocupação com as necessidades da vida, o temor das paixões tem que ter desaparecido; deve ter-se extinguido o simples interesse finito do sujeito, e a consciência tem de haver se desenvolvido muito, a fim de mostrar interesse por objetos universais (Hegel, 1990, p.71).

Hegel discute, nos seus textos de História da Filosofia e de Filosofia da História, a decadência dos impérios aparentemente fortes, mas interiormente mortos. A filosofia, portanto, surge do desencantamento do homem com o mundo terreno, ela opera a negação e a reconciliação do período de decadência da vida mundana no plano da espiritualidade. A razão em Hegel não está enclausurada em um mundo subjetivo e ideal, de acesso franqueado somente aos sábios versados na arte do raciocínio, tal como Platão a concebe. A razão está na história e expressa-se na cultura, pois o mundo é o que há de concreto na idéia, resultado do seu desenvolvimento e do seu processo de exteriorização. O universal não é somente um projeto, mas existe como objetividade, como ação: "o espírito que não se determina é uma abstração da inteligência” (Hegel, 1990, p.89).

\section{História da Filosofia: tempo histórico, ontologia e lógica}

Hegel afirma a necessidade de pensar a filosofia concomitantemente com as outras formas de manifestação cultural que edificam o espírito do mundo (weltgeist). Religião, arte, política, ciência, leis, entre outras manifestações da cultura, são expressões de um todo orgânico indissociável que permite ao historiador avaliar nas diferentes civilizações o grau de desenvolvimento atingido pelo espírito do povo (volksgeist). Não obstante, cabe à filosofia em cada época 
representar a consciência do espírito da época. A filosofia é a expressão cultural mais concreta do seu tempo, é o espírito na sua plena identidade e liberdade. A filosofia é a ciência "do pensamento necessário, de suas conexões e sistemas essenciais; é o conhecimento do que é verdadeiro e, por isso, eterno e imorredouro; pelo contrário, a história, segundo a representação mais corrente dela, tem que se ocupar do sucedido; portanto, do causal, do transitório e passado" (Hegel, 1986, p.162). O conhecimento histórico é necessário para a filosofia, visto que permite ao filósofo tomar consciência da gênese, do desenvolvimento e da ordem de necessidade da razão. A História da Filosofia tem características próprias na sua escritura, na medida em que o pensamento não necessita de nenhum referente externo (social, cultural, político e/ou econômico) para justificar a sua presença e a sua ação.

O conhecimento meramente histórico da filosofia não significa conhecimento da essência da filosofia. Assim, é inaceitável manifestar o pensamento em uma forma que não é a sua, ou seja, fazê-lo expressão de representações empíricas. $\mathrm{O}$ indivíduo é quem concretiza a obra do espírito, mas o indivíduo é o particular, enquanto o espírito é o universal. $\mathrm{O}$ universal realiza-se nas suas formas particulares, ou melhor, na desintegração das fases particulares o espírito ganha universalidade. O desenvolvimento do espírito é perceptível na história; portanto, a História da Filosofia é a filosofia com o acessório do tempo. A filosofia e a "história da filosofia são a mesma coisa, uma imagem (cópia) da outra. O estudo da história da filosofia é o estudo da própria filosofia, particularmente da lógica” (Hegel, 1986, p.44).

O longo trajeto percorrido pela humanidade vem fornecendo ao espírito as condições de reconhecimento da sua natureza. O espírito está fora do tempo porque é eterno, mas ele se descobre a si mesmo no tempo, num tempo de longa duração. As filosofias particulares, de Tales a Descartes, têm os limites das suas épocas, mas a filosofia é o resultado que enfeixa o processo de aprimoramento da idéia. Apreender esse movimento do espírito é o que possibilita a compreensão da racionalidade presente na história. Ao decifrar a lógica da história, ou melhor, a presença da lógica na história, torna-se possível compreender, a partir da ordem da necessidade e do processo de evolução, as ações aparentemente irracionais que os homens e os Estados produziram na história. A filosofia, por conseguinte, é lugar de inteligibilidade para apreender o racional em dois momentos: na sua condição de potência intemporal (idéia) e na sua condição de existência cultural exteriorizada no tempo (espírito).

À luz da concepção hegeliana, o saber (Ciência) que estuda o pensamento é a lógica, mas não somente de forma especulativa, considerando-o como um conteúdo psicológico, mas sim como produtor de todas as realidades. Em polêmica com Kant, Hegel afirma que a teoria da lógica não se esgota nas faculda- 
des do entendimento, pois ela deve ser compreendida como o processo de constituição do próprio sujeito. O processo de exteriorização da razão na história é lógico, ontológico e cronológico. O tempo histórico marca a existência e a experiência do Ser (ontologia) no processo de identificação entre as consciências subjetiva e objetiva, entre o sujeito e a razão. Neste processo, a contradição é o impulso para a tomada de consciência, pois, em oposição ao platonismo, Hegel não concebe o devir do sujeito como um olhar eterno para dentro de si mesmo; pelo contrário, o sujeito reconhece-se à medida que é impulsionado a se exteriorizar. O espírito encontra a sua liberdade no pensar puro, que contém a contradição permanente da alienação e da volta a si mesmo. É da natureza do espírito "alienar-se, para voltar a encontrar-se de novo" (Hegel, 1986, p. 36). É nessa dialética de autoconsciência e alienação, exteriorização e interiorização que o sujeito se produz como ser racional. $\mathrm{O}$ homem, que se vê estranho ao mundo social e natural que não compreende, passa a buscar o sentido racional e universal do mundo. O objetivo do espírito, encarnado nos homens particulares, é o autoconhecimento, e cada etapa da sua existência, das filosofias mais abstratas para as mais concretas, marca um estágio de desenvolvimento dessa meta fundamental. Na Fenomenologia do Espírito, Hegel apresenta a experiência da consciência subjetiva que se faz espírito, passando cada uma das fases da sua dramática ascensão. A Fenomenologia é a história do Pensamento na sua evolução. A obra procura demonstrar as características de cada fase do desenvolvimento da razão: da consciência sensível, da consciência imediata, do realismo ingênuo à autoconsciência plena do espírito, do Pensamento que se reconhece como Absoluto em si e para si. A obra produz esse movimento ontológico, histórico e lógico do ser reconhecendo-se como espírito, através desse processo de causalidade-dialética imanente ao processo da reflexão ${ }^{10}$.

Ao refletir sobre a realidade, os indivíduos exteriorizam o espírito na sua ação compreensiva que, à medida que se exterioriza, produz o universo da idealidade, o movimento da razão e do pensar. Pensar significa "produzir-se, sair fora de si” (Hegel, 1986, p. 31). Hegel não aceita a distinção entre o essencial e o inessencial, pois isto deixa a filosofia fragilizada diante da contestação dos cépticos: "Tudo é igualmente verdadeiro e real e daqui se deve partir [...] desaparecem as oposições entre Absoluto e o Sujeito, entre o Ser e a Razão e, aquela derivada, entre o Pensamento e o Discurso. O Absoluto é Sujeito, o Ser é Razão, o Pensamento é Discurso" (Châtelet, 1985, p.150). A experiência, na perspectiva empirista, não é desconsiderada, mas incorporada a uma experiência mais profunda: a experiência da razão que se conhece e, à medida que se conhece, controla-se e revela-se como discurso racional.

10. Segundo Châtelet, a dialética em Hegel não é método, mas a forma imanente de manifestação da razão, a única forma possível de explicitação do discurso da Ciência. 


\section{À guisa de conclusões}

Do ponto de vista da escrita da história poderíamos afirmar que a concepção de Hegel está associada a um conjunto de significados sobre o passado, sobre a história e sobre a sua escrita, que produziram grande impacto sobre a cultura historiográfica dos séculos XIX e XX. Os seus escritos refletem pensamentos densos e apresentados no interior de uma retórica repleta de imagens e de exemplos históricos, bíblicos, mitológicos e naturais que seduzem os leitores, por conformarem um estilo sofisticado e pleno de efeitos de verdade e de logicidade. Bertrand Russell, crítico contundente de Hegel na sua História da Filosofia Ocidental, afirmou que no final do século XIX “os principais filósofos acadêmicos, tanto na América como na Inglaterra, eram, em grande parte, hegelianos. Fora da filosofia pura, muitos teóricos protestantes adotavam as suas doutrinas, sendo que a sua filosofia da história afetou profundamente a teoria política” (Russell, 1967, p.274). Na seqüência do raciocínio, afirma que, embora "todas as doutrinas de Hegel (como creio) sejam falsas, conserva ele, não obstante, uma importância que não é meramente histórica, como melhor representante de certa classe de filosofia que, em outros, é menos coerente e menos compreensiva” (Russell, 1967, p.274). No final do capítulo dedicado ao pensamento de Hegel, após problematizar a arquitetura da lógica hegeliana, Russell afirma: "quanto pior é a lógica, mais interessantes são as conseqüências a que dá origem” (Russell, 1967, p. 291).

A fina ironia de Russell evidencia um sentimento ambíguo em relação a Hegel presente em muitos dos seus críticos. Marx, Dilthey e Croce, em diferentes situações e direções, manifestaram-se como críticos do caráter especulativo e metafísico da filosofia de Hegel; contudo, reconheceram o potencial metodológico do seu pensamento e, sobretudo, da sua percepção da centralidade da história na inteligibilidade do mundo social. Nesses termos, gostaríamos de afirmar que concebemos que a potencialidade da concepção hegeliana da história não está em uma pretensa originalidade das suas idéias; pelo contrário, seu poder de persuasão e, por extensão, de disseminação, nos séculos XIX e $\mathrm{XX}$, foram resultantes da sua capacidade de síntese de sentidos que perpassavam os discursos político, filosófico e, sobretudo, religioso, em circulação na atmosfera intelectual do período. Sendo assim, neste estudo, Hegel foi concebido como um autor que, tal como se manifestou Russell, expressou de forma sistematizada uma visão de mundo historicista presente de forma dispersa e fragmentada na cultura da reforma e do romantismo alemão que gradativamente e a partir de motivações e de interpretaçôes particulares difundiu-se no cenário intelectual europeu e americano. 
Por fim, a partir da análise que realizamos, gostaríamos de destacar seis características da concepção de história e de escrita da história hegeliana que esta exposição sintética das suas idéias evidenciou. Consideramos que a identificação e a compreensão desses sentidos subjacentes a esta representação da história são centrais para decifrar a forma de escrita prevalente na História da Filosofia que, em contextos particulares, impactou, também, outras formas de escrita da história, tais como a História das Idéias e, conforme hipótese deste estudo, a História das Idéias Pedagógicas. Primeiramente destacaremos o caráter escatológico dessa concepção que prevê uma gênese, um processo e um fim para a história. Para Hegel, o surgimento das cidades-Estados gregas, apoiadas em leis, indica o ponto de partida da saga da razão na história. O longo processo de exteriorização do espírito envolveu a ascensão e a decadência das civilizações helênica, romana e católica, culminando na Reforma, na Revolução Francesa e na organização do moderno Estado alemão. A crítica aos vieses germanófilo, eurocêntrico e estadolátrico, presentes no discurso hegeliano, não significou uma recusa nos termos da escrita da história da compreensão escatológica ${ }^{11}$. Os esforços na perspectiva de compreender a gênese, a linha de desenvolvimento e os fins lógicos e necessários da história marcaram a escrita da história ocidental. Os conceitos de evolução e de progresso conformam esta forma de pensar a história como um processo de desenvolvimento necessário e inexorável. A escatologia não é, evidentemente, uma criação de Hegel; contudo, a incorporação desta na sua filosofia da história conferiu autoridade filosófica e científica a essa representação marcadamente religiosa. Teorias sociais materialistas da segunda metade do século XIX, tais como o positivismo e parcela significativa da interpretação do marxismo, aderiram a essas percepções unidirecionais e deterministas da história.

O segundo aspecto, caro à tradição da História das Idéias Pedagógicas, é o viés idealista expresso na tese: a idéia (?d?a) é demiurga da história. Entendidas como arquétipo (Platão), representação (Descartes e Locke), weltanschauung (Dilthey) ou substância universal que se torna geist (Hegel), as idéias gozam de grande prestígio nas reflexôes sobre o legado da cultura ocidental entre as elites letradas. A História das Idéias e a História da Filosofia são campos disciplinares que evidenciam esse interesse pelo plano espiritual e pressupõem, com maior ou menor ênfase, a centralidade das idéias, particularmente daquelas associadas à arte, à religião, à ciência, à literatura e à filosofia. Parte significativa da cultura historiográfica, a partir do segundo quartel do século XX, moveu-se no intuito de contrapor-se a essa visão idealista, porém a força desse tipo de olhar

11. Usamos aqui o termo estadolatria, cunhado por Gramsci, para representar a crença hegeliana no Estado como portador dos interesses universais. A tese hegeliana sobre o papel do Estado moderno está exposta, particularmente, na obra Princípios da Filosofia do Direito. 
ultrapassou os domínios da pesquisa acadêmica e assumiu, na expressão de Marx, a consistência granítica das crenças populares ${ }^{12}$.

O terceiro ponto que destacaremos da filosofia de Hegel é a representação racionalista da história. A razão governa o mundo. Este é o princípio que Hegel afirma ter encontrado na filosofia de Anaxágoras, pois ele "foi o primeiro a afirmar que o noûs governa o mundo; mas só agora é que o homem conseguiu reconhecer que o pensamento deve reger a realidade espiritual. Que magnífica alvorada! Todos os seres pensantes celebraram esta época" (Hegel, 1955, p.401). $\mathrm{O}$ axioma da racionalidade do real e da realidade do racional conduziu a duas grandes e contraditórias linhas de problematização do passado. A primeira associada à perspectiva panteísta da história e às doutrinas filosófico-religiosas que atribuem tudo que existe e tudo que se passa no mundo à Providência divina. A razão, nesta chave de leitura, é representada como um ente abstrato e divino que governa o mundo. A segunda acepção veiculou-se ao projeto de estudo do passado como objeto das ciências, uma vez que a idéia de uma racionalidade inerente aos acontecimentos políticos e sociais foi assumida como uma forma de recusa da tese aristotélica do caráter acidental da história. Logo, mesmo rompendo com a presunção de uma razão demiurga, reconhece-se que existe uma lógica no comportamento social acessível ao entendimento humano. Nessa chave de leitura estruturaram-se diversas iniciativas de criação de um conhecimento rigoroso e científico dos fenômenos sociais pelas chamadas ciências humanas, bem como pela moderna historiografia acadêmica a partir do último quartel do século XIX.

Outro aspecto que depreendemos da análise dessa concepção é o seu horizonte universalista (holístico) da história. As histórias dos indivíduos, dos povos e das culturas particulares interessam na medida em que elas revelam o sentido de totalidade e de universalidade do mundo social. Hegel concilia metodologicamente a relação entre a parte e o todo ou entre o particular e o universal. Todas as experiências culturais fazem parte de um mesmo processo, de maneira que os povos, as culturas, as tradiçôes, as formas de educação ganham inteligibilidade à luz do movimento universal que une a paidéia grega à modernidade dos grandes palcos urbanos da cultura. As histórias nacionais ganham significado, quando pensadas como expressōes desse movimento, cabendo aos historiadores compreender o papel que desempenha cada cultura no concerto da civilização.

O quinto aspecto está associado ao objetivo pragmático do estudo da história em Hegel. O passado não interessa como passado, como acontecimento

12. Entre as correntes historiográficas que se moveram em oposição à interpretação idealista da história, podemos destacar a historiografia marxista e o movimento historiográfico associado à tradição de Annales. 
circunscrito ao seu tempo e lugar. O passado faz sentido pelo seu caráter edificante no presente, como processo de produçãa de conhecimentos dirigidos a fins práticos, sejam eles de ordem política, administrativa ou educativa. Essa tese levou Croce a afirmar que toda a história é história contemporânea, uma vez que esta é sempre um apelo ao nosso presente. A necessidade prática, moral é o único critério possível para compreender o interesse do homem pela sua história, fazendo desta, sempre história contemporânea (Croce, 1962, p.14). Da história extraímos liçóes e conhecimentos para agirmos dentro de linhas de ação plausíveis, pois informadas pela experiência e pelo conhecimento do passado. A história, nesta chave de leitura, não é um estudo desinteressado, tal como afirmaram os historiadores positivistas, mas sim uma obra engajada nos problemas do presente. Tal impostação impõe um permanente julgamento do passado a partir dos pressupostos filosóficos considerados oportunos no presente. Logo, o tão temido anacronismo torna-se a ação metodológica por excelência, ao passo que a pragmática (ação dirigida a fins) exige a permanente atualização do passado nos termos postos pelos projetos filosóficos, educativos e/ou políticos em curso no presente.

A última, mas não menos importante, das características inerentes à compreensão hegeliana pode ser representada pelo horizonte apaziguador da sua concepção dialética da história. Na sua maneira de entender, a decadência das civilizaçôes, a destruição dos impérios, as guerras, enfim, os acontecimentos trágicos são justificados como etapas necessárias do devir do espírito do mundo, reconciliando, assim, o homem com o seu passado. A história não é o espetáculo terrível das paixões ou o matadouro onde é imolada a sorte dos povos. Tal leitura, segundo Hegel, é uma ilusão da consciência subjetiva, incapaz de perceber as astúcias e os desígnios da razão. Hegel usa a imagem do mito da ave fênix que, queimada, renasce das suas próprias cinzas, para ilustrar os movimentos contraditórios, progressivos e positivos da história. Tal impostação se contrapõe, a um só tempo, à visão vichiana da circularidade da história (corso e ricorso) e ao juízo relativista sobre os valores culturais, que tanto incomodou os historiadores vinculados ao historicismo alemão, tais como Spengler e Troeltsch. Nessa perspectiva, a morte não significa o fim, mas sim uma etapa cumprida e, sobremaneira, um recomeço em condições qualitativamente superiores. As tragédias ensinam-nos e as experiências aperfeiçoam-nos, eis o caráter apaziguador da narrativa hegeliana. Hegel elaborou filosoficamente uma cosmovisão capaz de confortar e de justificar as agruras da experiência humana. As guerras e as revoluçōes, por exemplo, são tragédias do ponto de vista daqueles que perderam entes, posses ou direitos no decorrer desses acontecimentos; não obstante, podem ser e, de fato, foram interpretadas como etapas necessárias para o progresso da humanidade. 
Em síntese, podemos reiterar que a obra de Hegel reafirmou conceitualmente e metodologicamente as crenças na virtuosidade e no papel edificante das idéias, bem como produziu uma interpretação do passado capaz de apaziguar o sentimento de dilaceração da cultura, ao conciliar história, ontologia e lógica. Como afirmamos anteriormente, a escatologia, o idealismo, o racionalismo, o universalismo, o pragmatismo e a interpretação apaziguadora do passado representam sentidos presentes no cenário intelectual europeu em períodos muito anteriores a Hegel. Porém, ele foi capaz de sistematizá-los, dentro de uma teoria articulada e, sobretudo, capaz dialogar com múltiplas esferas sociais, tais como a acadêmica, a política, a religiosa e a cultural. A sua filosofia, de forma coerente com as suas idéias, exteriorizou-se, isto é, promoveu a vida cultural; e o impacto da sua visão de mundo pode ser mensurado pelo quilate daqueles que se opuseram às suas idéias sobre a história, tais como Nietzsche, que sustentou a tese de a história ser movida pela paixão; Marx, que defendeu o movimento das forças produtivas como leitmotiv do processo histórico; ou Dilthey, que reafirmou a idéia de geist, porém divergiu da representação de espírito como entidade abstrata e universal, ressignificando-o como expressão de força singular atuante no espaço e no tempo determinado e produzido pela própria experiência humana.

No plano da escrita da História da Educação - particularmente daquela que assumiu as idéias pedagógicas e/ou o pensamento educacional como foco principal das suas análises - , defendemos a hipótese de que os sentidos postos em circulação pela História da Filosofia e, particularmente, pela concepção hegeliana da história e da sua escrita encontram-se presentes nos textos da área, sejam eles manuais ou obras acadêmicas. A presença explícita e direta de Hegel como suporte da escrita da História da Educação não é um fenômeno freqüente, porém o processo de recepção e de assimilação de idéias no âmbito de uma cultura historiográfica envolve, em geral, uma dinâmica indireta e contraditória. Logo, baseados nos estudos que estamos realizando no campo da historiografia da educação brasileira e da história intelectual da educação, percebemos - com maior ou menor intensidade, explícita ou implicitamente; com maior ou menor rigor analítico, fazendo ou não referência às idéias hegelianas - a aproximação entre as escritas da História da Educação e da História da Filosofia. As análises historiográficas centradas em obras e em autores de referência da área poderão revelar em que grau e de que formas peculiares esses significados se fazem presentes objetivamente na construção das narrativas histórico-educacionais. Ainda que não nos tenhamos dedicado aqui a demonstrar analiticamente e historicamente os marcos desta relação, acreditamos ter contribuído na perspectiva de impostar uma chave de leitura das obras de História das Idéias Educacionais, que permanecem circulando e sendo produzidas em 
diferentes níveis de formação e de produção de conhecimento na área. A decifração e a estruturação desta concepção de história e dos sentidos subjacentes a ela, na forma de uma hipótese analítica, demandarão, evidentemente, o ajuste desta às condiçôes empíricas das pesquisas que pretenderem assumir em parte ou integralmente esta forma de problematização.

\section{Referências bibliográficas}

BARREIRA, Luis. História e historiografia: as escritas recentes da história da educação brasileira (1971-1988). 1995. Tese (Doutorado em História da Educação) - Universidade Estadual de Campinas, Campinas, 1995.

CARVALHO, M. M. A História da Educação no Brasil. In: CARVALHO, M. M. A escola e a república e outros ensaios. Bragança Paulista: EDUSF, 2003. p. 281-312.

CHÂTELET, François. O pensamento de Hegel. 2. ed. Lisboa: Presença, 1985.

CROCE, Benedetto. A história, pensamento e ação. Rio de Janeiro: Zahar, 1962.

FARIA FILHO, L. M.; VIDAL, D. História da Educação no Brasil: a constituição histórica do campo (1880-1970). Revista Brasileira de História, São Paulo, v. 23, n. 45, p. 37-70, 2003.

GONDRA, José. Pesquisa em História da Educação no Brasil. Rio de Janeiro: LP\&M, 2006.

HEGEL, Georg Wilhelm Friedrich. Lecciones sobre la historia de la filosofia. México: Fondo de Cultura Económico, 1955.

HEGEL, Georg Wilhelm Friedrich. Princípios da filosofia do direito. Lisboa: Martins Fontes, 1976.

HEGEL, Georg Wilhelm Friedrich. Introdução à História da Filosofia. Rio de Janeiro: Tecnoprint, 1986.

HEGEL, Georg Wilhelm Friedrich. A razão na história: uma introdução geral à filosofia da história. São Paulo: Moraes, 1990.

HEGEL, Georg Wilhelm Friedrich. Fenomenologia do espirito. 2. ed. Petrópolis: Vozes, 1992.

HYPPOLITE, Jean. Genesi e struttura della fenomenologia dello spirito di Hegel. Firenze: La Nuova Italia, 1972.

IGGERS, George G. The German conception of History: The national tradition of historical thought from herder to the present. Middleton: Wesleyan University Press, 1983.

KELLEY, Donald R. The descent of ideas: the history of intellectual history. Burlington: Ashgate, 2002.

KRUGER, Lorenz. Por qué estudiamos la historia de la filosofia? In: SKINNER, Quentin (Org.). La filosofia en la historia: ensayos de historiografía de la filosofía. Barcelona: Paidós, 1990. 
KUBRICK, Bruce. Siete pensadores y como crecieron: Descartes, Espinoza, Leibniz; Locke, Berkeley, Hume; Kant. In: SKINNER, Quentin (Org.). La filosofia en la historia: ensayos de historiografía de la filosofía. Barcelona: Paidós, 1990.

MAC INTYRE, Alasdair. La relación de la filosofia con su passado. In: SKINNER, Quentin (Org.) et al. La filosofia en la historia: ensayos de historiografía de la filosofía. Barcelona: Paidós, 1990.

NUNES, C. Ensino e historiografia da educação: problematização de uma hipótese. Revista brasileira de educação, n.1, p.67-79, 1996.

RUSSELL, Bertrand. História da Filosofia Ocidental. São Paulo: Companhia Editora Nacional, $1967.5 \mathrm{v}$.

SKINNER, Quentin et al. (Org.) La filosofia en la historia: ensayos de historiografia de la filosofia. Barcelona: Paidós, 1990.

VIEIRA, Carlos Eduardo. Historicismo, cultura e formação humana no pensamento de Antonio Gramsci. São Paulo: 1999. Tese (Doutorado em História e Filosofia da Educação) - Pontifícia Universidade Católica de São Paulo, São Paulo, 1999.

VIEIRA, Carlos Eduardo; ROBALLO, Roberlayne de Oliveira Borges. História e História da Educação no projeto de formação de professores na década de trinta no Brasil: problematizando as Noções de Afrânio Peixoto. Inter-ação, Goiânia, v. 32, p.243-260, 2008.

WARDE, M. J. Questôes teóricas e de método: a História da Educação nos marcos de uma disciplina. In: SAVIANI, D.; LOMBARDI, J. C.; SANFELICE, J. L. (Org.). História e Historiografia da Educação: o debate teórico-metodológico atual. Campinas: Autores Associados, 1998.

Recebido em 26 de junho de 2008 e aprovado em 20 de janeiro de 2009. 